\title{
我
}

\section{Long-term and Short-term AC Treeing Breakdown of Epoxy/Micro-Silica/Nano-Silicate Composite in Needle- Plate Electrodes}

\author{
Jae-Jun Park ${ }^{\dagger}$ \\ Department of Electrical and Electronic Engineering, Joongbu University, Geumsan 312-702, Korea
}

Received August 29, 2012; Accepted September 11, 2012

\begin{abstract}
In order to characterize insulation properties of epoxy/micro-silica/nano-silicate composite (EMNC), long-term and short-term AC treeing tests were carried out undr non-uniform electric field generated between needle-plate electrodes. In a long-term test, a $10 \mathrm{kV}(60 \mathrm{~Hz})$ electrical field was applied to the specimen positioned between the electrodes with a distance of $2.7 \mathrm{~mm}$ in an insulating oil bath at $30^{\circ} \mathrm{C}$, and a typical branch type electrical tree was observed in the neat epoxy resin and breakdown took place at 1,042 min after applying the $10 \mathrm{kVelectrical}$ field. Meanwhile, the spherical tree with the tree length of $237 \mu \mathrm{m}$ was seen in EMNC-65-0.3 at 52,380 min (36.4 day) and then the test was stopped because the tree propagation rate was too low. In the short-term test, an electrial field was applied to a $3.5 \mathrm{~mm}$-thick specimen at an increasing voltage rate of $0.5 \mathrm{kV} / \mathrm{s}$ until breakdown in insulating oil bath at $30^{\circ} \mathrm{C}$ and $130^{\circ} \mathrm{C}$, and the data was estimated by Weibull statistical analysis. The electrical insulation breakdown strength for neat epoxy resin was $1,763 \mathrm{kV} / \mathrm{mm}$ at $30^{\circ} \mathrm{C}$, while that for EMNC-65-0.3 was 2,604 kV/mm, which was a modified value of $47 \%$. As was expected, the breakdown strength decreased at higher test temperatures.
\end{abstract}

Keywords: Electrical treeing, Electrical insulation breakdown strength, Epoxy/micro-silica/nano-silicate composites, Layered silicate, Weibull statistical analysis

\section{INTRODUCTION}

Epoxy resins are well-known materials in the field of insulation systems for heavy electric equipments, because they have good mechanical and thermal properties as well as excellent electrical properties [1-3]. In the last two decades, many researchers have developed new epoxy-based composites considering much higher performance with lower cost in electrical applications, and they found that the loading of micro-silica particles improves dimensional stability, and mechanical and thermal properties of the neat epoxy systems during their manufacturing process or service lives. Messersmith and Giannelis [4] reported that the

${ }^{\dagger}$ Author to whom all correspondence should be addressed: E-mail: jjpark@joongbu.ac.kr

Copyright @2012 KIEEME. All rights reserved.

This is an open-access article distributed under the terms of the Creative Commons Attribution Non-Commercial
License (http://creativecommons.org/licenses/by-nc/3.0) which permits unrestricted noncommercial use, Llicense hinte://) reativecommons.org/icenses/lby-nc/3.o) which permits unrestricted
distribution, and reproduction in any medium, provided the original work is properly cited storage modulus of epoxy resin increased $58 \%$ at the glass transition region and increased $450 \%$ at the rubbery plateau region by loading only 4 vol.\% of clay. Mülhaupt and co-workers [5] demonstrated that toughness and stiffness of epoxy resin were modified by adding nano-sized mica, bentonite or hectorite. T. Tanaka and co-workers [6] demonstrated that epoxy/layered silicate nanocomposite had much better insulation breakdown strength than that of the nonfilled epoxy resin system in needle-plate electrodes geometry. We have already reported that its insulation breakdown strength was $33 \%$ higher than that of the system without nano-silicate [7].

Since the 1950s, after the electrical tree was first found in polymer insulation materials, electrical treeing breakdown and its phenomena were investigated in non-uniform electric fields in order to estimate the insulation property in solid insulators, because it was often referred as the most important mechanism for the deterioration of polymeric insulators (e.g. high voltage polymeric cables) [8-11]. The tree growth mechanism was divided into three processes: (1) incubation process, (2) initiation 
process, and (3) propagation process. Once an electrical tree was initiated, it would be propagated rapidly and finally, the breakdown occurred. Hence, the initiation time and the propagation rate should be delayed in order to acquire good insulation polymeric materials.

In this study, a multilayered silicate was exfoliated in an epoxy resin by our electric field method [12] and it was mixed into an epoxy/micro-silica composite (EMC) in order to prepare epoxy/ micro-silica/nano-silicate composite (EMNC), and then longterm and short-term AC treeing tests were carried out under a non-uniform electric field generated between needle-plate electrodes in order to characterize insulation properties of the composites.

\section{EXPERIMENTS}

\subsection{Materials}

A commercial DGEBA (diglycidyl ether of bisphenol A) type epoxy resin, YD 128 (Kukdo Chem. Co.) was used. The equivalent weight was $184 \sim 190$ and the viscosity was $11,500 \sim 13,500 \mathrm{cps}$ at $25^{\circ} \mathrm{C}$. The curing agent was Me-THPA (3- or 4-methyl-1,2,3,6tetrahydrophthalic anhydride) whose grade name was $\mathrm{HN}$ 2200 (Hitachi Chem. Co.). It is widely used in the field of electric insulation. The accelerator was BDMA (benzyl-dimethyl amine, Kukdo Chem. Co.).

Cloisite ${ }^{\circledR} 10$ A (Southern Clay Products, Inc., USA) was used as a multilayered silicate, which was a natural montmorillonite modified with 2MBHT (dimethyl-benzyl-hydrogenated tallow quaternary ammonium) as a sort of quaternary ammonium salt. Micro-silica whose average particle size was $2 \mu \mathrm{m}$, was purchased from Kosem co. (Korea) in the product name of CA0020. The inorganic fillers were dried at $110^{\circ} \mathrm{C}$ for $24 \mathrm{~h}$ in a vacuum oven and stored in a desiccator before use.

A needle-type steel electrode was purchased from Ogura Jewelry Co., Japan. Its diameter and length were $1 \mathrm{~mm}$ and $60 \mathrm{~mm}$, respectively, with a tip angle of $30^{\circ}$ and a curvature radius of 5 $\mu \mathrm{m}$.

\subsection{Specimen preparation for AC treeing test}

In order to prepare EMNC, DGEBA (8.4 g) and Cloisite $10 \mathrm{~A}$ (1.0g) were well-mixed in a bottle with a mechanical agitator for $30 \mathrm{~min}$ and then they were treated by an AC electric field process developed by us [12]. The AC electric field was generated by a high voltage (HV) generator in the following conditions; (1) inter-electrode distance: $50 \mathrm{~mm}$, (2) application voltage: $11 \mathrm{kV}$, (3) frequency: $1 \mathrm{kHz}$, and (4) application time: $60 \mathrm{~min}$. During the AC application time, epoxy resin penetrated into the interlayer making the multilayered silicate swollen. Then, it was degassed in a vacuum oven for $30 \mathrm{~min}$. On the other hand, DGEBA (10 g) and micro-silica (65 g) in another bottle were well-mixed with a high-speed agitator at 5,000 rpm for $30 \mathrm{~min}$, and then the mixture in the first bottle and THPA (15.6 g) were added to the bottle at 1,000 rpm for $30 \mathrm{~min}$. Finally, BDMA ( $0.9 \mathrm{~g})$ was mixed for 5 min. The weight ratios of micro-silica and nano-silicate were 65 wt\% and $0.3 \mathrm{wt} \%$, and it was denoted as EMNC-65-0.3. Another mixture denoted as EMNC-60-0.3 was prepared by mixing epoxy with micro-silica (60 wt\%) and nano-silicate $(0.3 \mathrm{wt} \%)$ through the same procedure of EMNC-65-03.

The mixture was poured into a mould having a cavity of $15 \times 15$ $\mathrm{mm}^{2}$ and a height of $30 \mathrm{~mm}$, in which a needle electrode was arranged beforehand to make the distance of needle-plate electrodes $2.7 \mathrm{~mm}$ (for long-term test) or $3.5 \mathrm{~mm}$ (for short-term test). Then, it was cured at $120^{\circ} \mathrm{C}$ for $2 \mathrm{hr}$ and continually post- cured at $150^{\circ} \mathrm{C}$ for $2 \mathrm{hr}$. Afterwards, it was cooled slowly at a rate of $-0.5{ }^{\circ} \mathrm{C} / \mathrm{min}$ until room temperature to avoid internal stress. Finally, the opposite-side of the needle electrode in the specimen was coated with the conductive silver paste [6].

\subsection{AC treeing test}

To carry out the long-term test, the specimen with $2.7 \mathrm{~mm}$ thick insulation was dipped into a $30^{\circ} \mathrm{C}$ insulating oil bath for 2 $\mathrm{hr}$ and then a $10 \mathrm{kV}(60 \mathrm{~Hz})$ AC electric field was applied to the specimen in the needle-plate electrode arrangement. It was monitored by a video microscope system (ICS-305B, SOMETECH Inc.). High voltage (HV) was applied by the AC Endurance Voltage Tester (Haefely, Germany) at a rising speed of $1 \mathrm{kV} / \mathrm{s}$ until 10 $\mathrm{kV}$ and kept the test voltage. The tree images were collected every $1 \mathrm{~min}$.

To carry out the short-term test, the specimen with $3.5 \mathrm{~mm}$ thick insulation was dipped into $30^{\circ} \mathrm{C}$ or $130^{\circ} \mathrm{C}$ insulating oil bath for $2 \mathrm{hr}$ and then AC electrical field was applied to the specimen at an increasing voltage rate of $0.5 \mathrm{kV} / \mathrm{s}$ until breakdown in insulating oil bath at $30^{\circ} \mathrm{C}$ and $130^{\circ} \mathrm{C}$. All the breakdown data was estimated by Weibull statistical analysis.

\subsection{SEM observation}

Field emission scanning electron microscopy (FE-SEM, JMS$6701 \mathrm{~F}$, JEOL) was used at an acceleration voltage of $10 \mathrm{kV}$ in order to confirm the well-dispersion of micro-silica and good interfacial morphology between epoxy and micro-silica.

\section{RESULTS AND DISCUSSION}

In order to evaluate the positive effect of the ac electric field application on the exfoliation of the multilayered silicate, wideangle X-ray diffraction (WAXD) analysis and transmission electron microscopy (TEM) observation for the cured epoxy matrix/ Cloisite 10 A system were performed, and it was found that the multilayered order became an exfoliated disorder [6], which was not displayed in this paper. It implied that the applied AC electric field was acted as a driving force for the exfoliation of the multilayered silicate so that EMNCs could be obtained.

To convert the applied high voltage to the applied electrical field, $\mathrm{E}_{\text {tip }}$ at the needle tip generated in the needle-plate electrodes, the following Masons formula [13] was used.

$$
E_{t i p}=\frac{2 V}{r \bullet \ln (1+4 x / r)}
$$

where, $\mathrm{E}_{\text {tip }}$ was applied electrical field at the needle tip, $\mathrm{V}$ was applied voltage, $\mathrm{r}$ was needle tip radius, and $\mathrm{x}$ was the distance between needle-plate electrodes. In the long-term test, if the values $r=5 \mu \mathrm{m}, \mathrm{V}=10 \mathrm{kV}$ and $\mathrm{x}=2,700 \mu \mathrm{m}$ were introduced to the Masons formula, the electrical field value at the needle tip, $\mathrm{E}_{\text {tip }}$ was to be $520.9 \mathrm{kV} / \mathrm{mm}$.

Figures 1(a) and 1(b) show electrical trees captured after applying constant electric field of $520.9 \mathrm{kV} / \mathrm{mm}(60 \mathrm{~Hz})$ at $30^{\circ} \mathrm{C}$ for (a) 1,041 min (0.72 day) and (b) 1,042 min (insulation breakdown) in the neat epoxy resin. The branch type electrical tree was initiated at $650 \mathrm{~min}$ and propagated rapidly at the speed of $6.89 \mu \mathrm{m} / \mathrm{min}$, and finally breakdown took place at 1,042 min after applying $520.9 \mathrm{kV} / \mathrm{mm}$. Meanwhile, the spherical tree with the tree length of $283 \mu \mathrm{m}$ was seen in EMNC-60-0.3 at 52,380 min (36.4 day) and the same tree type with the shorter tree length, $237 \mu$ m was seen in EMNC-65-0.3 at 52,380 min (36.4 day). The long-term test for 

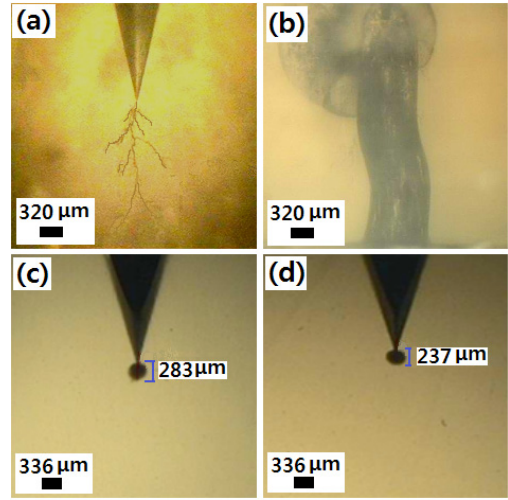

Fig. 1. Electrical trees were captured after applying a constant electric field of $520.9 \mathrm{kV} / \mathrm{mm}(60 \mathrm{~Hz})$ at $30^{\circ} \mathrm{C}$ for (a) $1,041 \mathrm{~min}$ (0.72 day), (b) 1,042 min (insulation breakdown) in the neat epoxy resin, (c) 52,380 min (36.4 day) in EMNC-60-0.3, and for (d) 52,380 min (36.4 day) in EMNC-65-0.3.
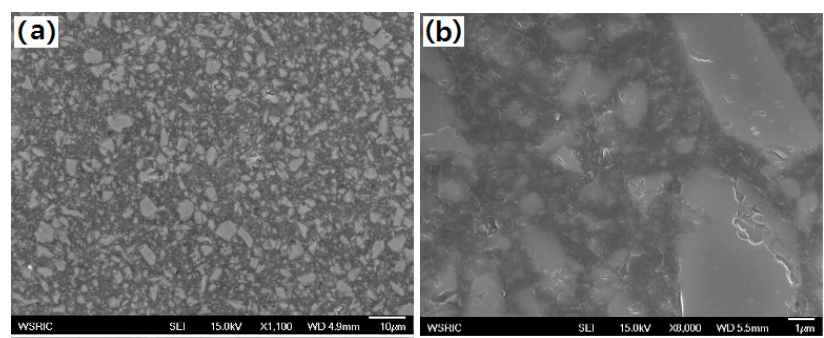

Fig. 2. (a) SEM of the microstructure of the EMNC-65-0.3 and (b) its magnified image.

the last two systems was stopped because the tree propagation rate was too low.

In the neat epoxy resin, charges were injected from the needle tip to the epoxy insulation and then inversely extracted from the epoxy insulation to the needle tip cyclically, and then small branches of the electrical tree were initiated from the needle tip. Then, as charges were injected to the epoxy insulation from the carbonized conductive tree tip and inversely and extracted, several new branches appeared, and they grew rapidly and became fatter and darker (Fig. 1(a)) throughout the propagation process. Finally, the penetration breakdown took place (Fig. 1(b)). In the EMNCs, on the contrary, the tree growth was blocked by the well-dispersed micro-silica and nano-silicate; therefore the tree growth direction was frequently changed at many points so that the morphology of the tree type became a spherical tree. That is, if an electrical tree was blocked by a silica particle, the tree should develop a new root. The barrier effect of silica on the tree growth rate was higher in the system with high silica content, and it meant that the interface between epoxy and silica or silicate was very good, for if the interface was bad, the strength of the electrical breakdown became lower [14].

To confirm the well-dispersion of micro-silica and good interfacial morphology between epoxy and micro-silica, the SEM of the microstructure regarding the EMNC-65-0.3 was shown in Fig. 2(a) and its magnified image was displayed in Fig. 2(b). Large particles were well-dispersed and smaller particles (less than 2 $\mu \mathrm{m})$ were well-dispersed among the large particles. In addition, it was shown that the interface between epoxy and silica was good. When a micro-silica was added to an epoxy matrix, the microsilica could anchor the epoxy chains by the hydrogen bonding between silanol groups on the silica surface and hydroxyl groups

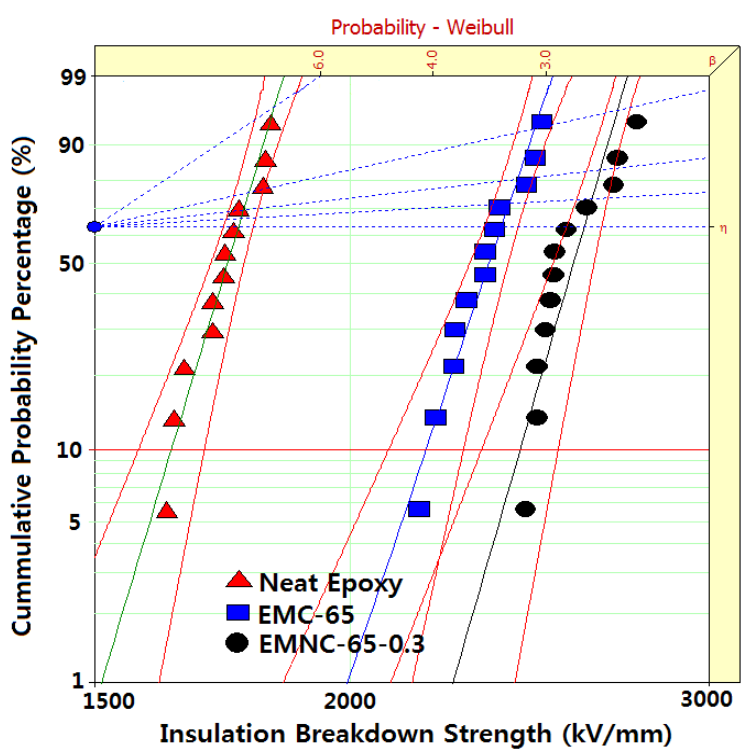

Fig. 3. Weibull statistical analyses of insulation breakdown strength for neat epoxy, EMC-65 and EMNC-65-0.3 at $30^{\circ} \mathrm{C}$.

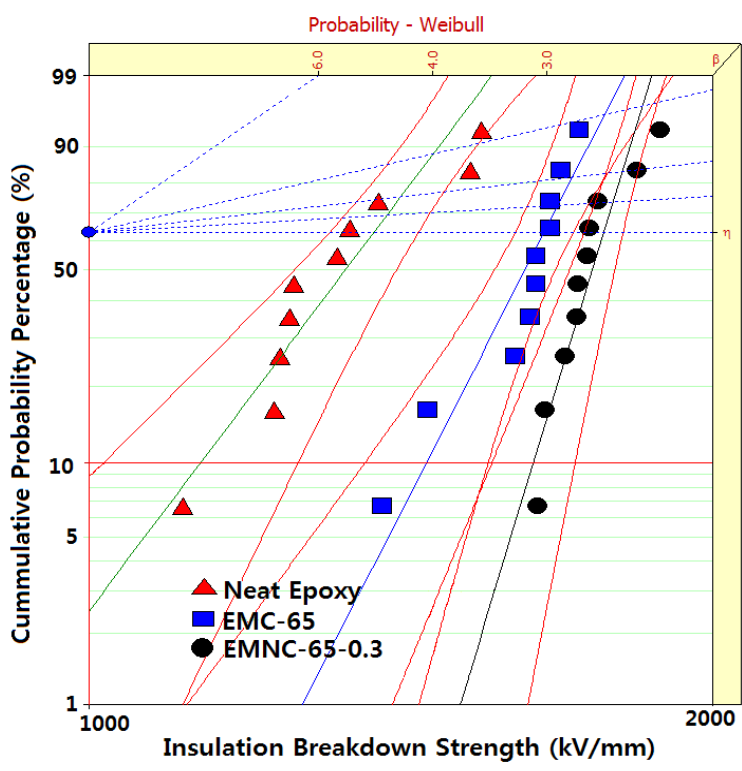

Fig. 4. Weibull statistical analyses of insulation breakdown strength for neat epoxy, EMC-65 and EMNC-65-0.3 at $130^{\circ} \mathrm{C}$.

in the epoxy matrix so that the interfacial characteristics became good. Therefore, the barrier effect of the silica on the tree growth rate was good.

In the short-term test at $30^{\circ} \mathrm{C}$, Weibull statistical analyses of the insulation breakdown strength for neat epoxy, EMC-65 and EMC-65-0.3 was shown in Fig. 3 and the parameters such as shape, scale parameters, and B10 value were obtained from the Weibull plots. Here, the shape parameter could be obtained from the slope meaning the data distribution, and the scale parameter represented the insulation breakdown strength by which $63.2 \%$ of the cumulative probability was expected to breakdown. The B10 value referred to the insulation breakdown strength at which $10 \%$ would fail (that is, $90 \%$ would survive) under the increasing voltage rate of $0.5 \mathrm{kV} / \mathrm{s}$ until breakdown. The statistical analysis revealed that the scale parameter of the neat epoxy was 1,763 $\mathrm{kV} / \mathrm{mm}$ with the shape parameter of 29.8 , and that of the EMC- 
Table 1. Weibull parameters for insulation breakdown strength in neat epoxy, EMC-65 and EMNC-65-0.3 at $30{ }^{\circ} \mathrm{C}$ obtained from Fig. 3.

\begin{tabular}{cccc}
\hline System & $\begin{array}{c}\text { Scale Parameter } \\
(\mathrm{kV} / \mathrm{mm})\end{array}$ & Shape Parameter & $\begin{array}{c}\text { B10 Value } \\
(\mathrm{kV} / \mathrm{mm})\end{array}$ \\
\hline Neat Epoxy & 1,763 & 29.8 & 1,635 \\
EMC-65 & 2,372 & 26.5 & 2,178 \\
ENMC-65-0.3 & 2,604 & 31.1 & 2,421 \\
\hline
\end{tabular}

Table 2. Weibull parameters for insulation breakdown strength in neat epoxy, EMC-65 and EMNC-65-0.3 at $130^{\circ} \mathrm{C}$ obtained from Figure 4.

\begin{tabular}{cccc}
\hline System & $\begin{array}{c}\text { Scale Parameter } \\
(\mathrm{kV} / \mathrm{mm})\end{array}$ & Shape Parameter & $\begin{array}{c}\text { B10 Value } \\
(\mathrm{kV} / \mathrm{mm})\end{array}$ \\
\hline \hline Neat Epoxy & 1,373 & 11.6 & 1,132 \\
EMC-65 & 1,658 & 17.2 & 1,455 \\
ENMC-65-0.3 & 1,772 & 28.8 & 1,638 \\
\hline
\end{tabular}

65 was $2,372 \mathrm{kV} / \mathrm{min}$ with the shape parameter of 16.5 . As was expected, a $34 \%$ increase in insulation breakdown strength was obtained by the addition of micro-silica. The scale parameter was further modified by the addition of nano-silicate and its value was 2,604 kV/min in EMNC-65-0.3, where it was increased by $47 \%$ compared to the value of neat epoxy resin and by $11 \% \mathrm{com}$ pared to the value of EMC-65. When a micro-silica was added to an epoxy matrix, the interfacial characteristics between epoxy and micro-silica was good and the micro-silica could block the tree growth so that the insulation breakdown strength increased. These results meant that the nano layered silicates were acted as good barriers.

It was because the nano layered silicates were packed into the micro-silica particles of Fig. 2 and the barrier effect increased.

The Weibull parameters obtained from Fig. 3 were listed on Table 1.

To study the effect of atmospheric temperature, short-term tests for neat epoxy, EMC-65 and EMC-65-0.3 were carried out at $130{ }^{\circ} \mathrm{C}$ and the insulation breakdown strength data were introduced to Weibull statistical analyses. Also, the parameters were listed on Table 2. As shown in Fig. 3, the scale parameter increased as micro-silica was added, and the parameter was more modified by the addition of nano-silicate. The scale parameters for neat epoxy, EMC-65 and EMC-65-0.3 were 1,373 kV/min, 1,658 $\mathrm{kV} / \mathrm{min}$, and $1,772 \mathrm{kV} / \mathrm{min}$, respectively. The highest value for EMNC-65-0.3 was 29\% higher than that of the neat epoxy.

When the atmospheric temperature incressed, the scale parameters for neat epoxy, EMC-65 and EMC-65-0.3 decreased $22 \%, 30 \%$ and $32 \%$, respectively, compared to the values at $30^{\circ} \mathrm{C}$. It was because the short-time test was carried out over the glass transition temperature ( $\mathrm{Tg}$ ). (Tg of the neat epoxy resin was $127^{\circ} \mathrm{C}$.) That is, if a polymer was over Tg, the free volume increased so that the mobility of the polymer chains increased. Therefore, electrons ejected from the needle tip could easily pass the insulator.

\section{CONCLUSIONS}

A new insulation material for heavy electrical equipment was prepared by mixing the epoxy matrix, micro-silica and nanosized layered silicate, where nano-sized silicate was pre-prepared from the multilayered silicate via our electric field dispersion process. Then, long-term and short-term AC treeing tests were carried out under a non-uniform electric field generated between needle-plate electrodes. In the long-term test, a typical branch type electrical tree was observed in the neat epoxy resin and breakdown took place at 1,042 min after applying $10 \mathrm{kV}$. Meanwhile, the spherical tree with the tree length of $237 \mu \mathrm{m}$ was seen in EMNC-65-0.3 at 52,380 min (36.4 day). In the short-term test, the strength of electrical insulation breakdown regarding neat epoxy resin was $1,763 \mathrm{kV} / \mathrm{mm}$ at $30^{\circ} \mathrm{C}$, while that for EMNC$65-0.3$ was $2,604 \mathrm{kV} / \mathrm{mm}$, which was a $47 \%$ modified value. As was expected, the breakdown strength decreased at higher test temperatures.

\section{ACKNOWLEDGMENT}

This work was supported by the Joongbu University (2012).

\section{REFERENCES}

[1] J. Y. Lee, M. J. Shim and S. W. Kim, Polym. Eng. Sci., 39, 1993 (1999) [DOI: 10.1002/pen.11592].

[2] Y. S. Cho, M. J. Shim and S. W. Kim, Mater. Chem. Phys., 66, 70 (2000) [DOI: http://dx.doi.org/10.1016/S0254-0584(00)00272-8].

[3] R. Sarathi, R. K. Sahu and P. Rajeshkumar, Mater. Sci. Eng.: A, 445, 567 (2007) [DOI: http://dx.doi.org/10.1016/ j.msea.2006.09.077].

[4] P. B. Messersmith and E. P. Giannelis, Chem. Mater., 6, 1719 (1994) [DOI: 10.1021/cm00046a026].

[5] C. Zilg, R. Mülhaupt, and J. Finter, Macromol. Chem. Phys., 200, 661 (1999) [DOI: 10.1002/(SICI)1521-3935(19990301].

[6] T. Imai, F. Sawa, T. Ozaki, T. Shimizu, R. Kido, M. Kozako, and T. Tanaka, IEEE Transactions on Dielectrics and Electrical Insulation, 13, 445 (2006) [DOI: 10.1109/TDEI.2006.1624291].

[7] J. J. Park, C. H. Lee, J. Y. Lee and H. D. Kim, IEEE Trans. Dielectr. Electr. Insul., 18, 667 (2011) [DOI: 10.1109/TDEI.2011.5931051].

[8] T. Imai, F. Sawa, T. Yoshimitsu, T. Ozaki, and T. Shimizu, IEEE Annual Report Conference on CEIDP, p.239 (2004).

[9] T. Tanaka, IEEE Transactions on Dielectrics and Electrical Insulation, 9, 704 (2002) [DOI: 10.1109/TDEI.2002.1038658].

[10] R. Vogelsan, T. Farr, and K. Frohlich, IEEE Transactions on Dielectrics and Electrical Insulation, 13, 373 (2006) [DOI: 10.1109/ TDEI.2006.1624282].

[11] L. A. Dissado, IEEE Transactions on Dielectrics and Electrical Insulation, 9, 483 (2002) [DOI: 10.1109/TDEI.2002.1024425].

[12] J. J. Park and J. Y. Lee, IEEE Trans. Dielectr. Electr. Insul. 17, 1516 (2010) [DOI: 10.1109/TDEI.2010.5595553].

[13] K. Theodosiou and I. Gialas, J. Electr. Eng., 59, 248 (2008).

[14] P. Barber, S. Balasubramanian, Y. Anguchamy, S. Gong, A. Wibowo, H. Gao, H. J. Ploehn and H. C. zur Loye, Materials, 2, 1697 (2009) [DOI: 10.3390/ma2041697]. 